\title{
For Manufacturing Enterprises of Third party Logistics Services Capability Evaluation Research
}

\author{
Yang Hao \\ School of computing \\ Shengyang Aerospace University \\ Shengyang China
}

\author{
Zhao Rong \\ School of Economic and Management \\ Shengyang Aerospace University \\ Shengyang China
}

\begin{abstract}
Manufacturing enterprises are the basis of our country. The competence of manufacturing enterprises is the basis of our country's international competence.So,it's of vital importance to study the competence of manufacturing enterprises.Core competence is the ability to operate efficiently within the business environment and also the ability to respond to challenges.In order to respond to challenges surrounding their business,managers are dedicating to build their core competencies. The third part logistic is the best way to reduce the cost and enhance the core competence of manufacturing enterprises.It is called"the third profits headspring".3PL develops well in the western countries and contributes to the benefits of west enterprises.But in China,it is a new industry and needs more attention to its development. It is a worthy research topic to how to choose logistics service suppliers and how to evaluate the service ability in this paper.Facing manufacturing,studied the evaluation system of service ability of third-party logistics enterprises,and constracted a service evaluation model by the Analytical Hierarchy Process. Through the evaluation model, logistics service enterprises call find the key elements affecting service ability,then improve the company's service ability by controlling the elements.
\end{abstract}

Keywords-Analytic Hierarchy Process; Manufacturer; Service Capacity; Third-Party Logistics

\section{INTRODUCTION}

\section{A. Concept of the third-party logistics}

The third-party logistics means that manufacturing enterprises authorize logistics dealt with by themselves before to professional logistics service provider in the form of contract in order to focus attention on their major business .Ma Xuefen et al. thought that third-party logistics means that logistics service is supplied by a third party other than supplier and purchaser. They provide personalized service for end users at a particular price in a stipulated period.

\section{B. Feature of logistics service in manufacturing enterprises}

According to the content, logistics in manufacturing enterprises is complex and professional. It has several features as follows,

High complexity and specialty.

Taking the manufacturing enterprises as the core;
A high request for the third-party supplier in terms of informatization.

\section{CONSTRUCTION OF EVALUATION INDEX SYSTEM FOR THE SERVICE COMPETENCE OF THIRD-PARTY LOGISTICS IN MANUFACTURING ENTERPRISES.}

\section{A. Principle for the construction of index system}

In the actual operation, to set up a evaluation index system effectively address manufacturing enterprises, general rules should be followed. It should be scientific, expandable,comprehensive and easy to be operated, with combination of quantitive and qualitative.

Construction of the evaluation index system for the supplier of manufacturing enterprises should adhere to the following principles.

systematic and comprehensive. It means that the evaluation index system should reflect various conditions of supplier comprehensively and accurately.

Flexible operability. It means that the evaluation system should be flexible rather than unchanged. And it should be determined and implemented according to the features and actual conditions of manufacturing enterprises.

Scientific and practical. It means that the evaluation system should reflect the actual conditions of production and operation of supplier scientifically and practically.

Expansibility. It means that the evaluation system built before can be adjusted in terms of quantity and contents according to market environment, customers' requests and operational needs of enterprise self.

\section{B. Construction of the evaluation index system for the service competence of third-party logistics service providers.}

According to service economy theory, third-party logistics service should possess the following features other than the basic feature of service. They are subordination, immediacy, mobility and depressiveness, high volatility of needs and fungibility. Therefore, the third-party logistics service should be subject to the main logistics of owner enterprise. In the actual situation, service competence of third-party logistics service provider should match the requirements with enterprise. Due to the characteristic of service, managers in the third-party logistics should make policies service-oriented and take third-party logistics service as a product so that to attach importance to its service quality.

Structure of the evaluation index system for the supplier of the third-party logistics is built according to the 
features of third-party logistics and guided by the principles above.

\section{METHODS RESEARCH ON THE SER VICE COMPETENCE EVALUATION OF THE THIRD-PARTY LOGISTICS SERVICE PROVIDER.}

\section{A. Brief introduction to the relevant evaluation methods}

At present, most manufacturing and commercial enterprises adopt qualitative method rather than quantitative method when evaluate service competence of third-party logistics provider. The paper will adopt widely used method AHP addressing the multilayer index evaluation of logistics provider.

\section{1) $\mathrm{KPI}$}

KPI means that performance index of one enterprise should be connected to its strategy. "key" means the key problems that need to be resolved strategically during a period. Performance evaluation system design evaluation index according to these problems

\section{2) $D E A$}

DEA, short for Data Envelopment Analysis, was presented by American operational experts Charnes, Cooper et al. in 1978. It is used to research the relative efficiency DMU of "more output with more input".

\section{3) $A H P$}

The basic idea of this method is to arrange various elements into several layers from top to down according to their importance and quantize importance of elements on each layer so that to form an order of importance and set them as the final decision basis one by one. The following part will evaluate various index according to this method.

\section{B. Analysis of applicability of AHP}

AHP is a widely used evaluation method at present. It is adopted in the paper to evaluate and analyze the service competence of third-party logistics service provider

\section{1) AHP and its principle}

The theory of AHP was put forward by Saaty in the early 1970s. In his opinion, each large system can be divided into small ones in terms of space and time. Start from the feature of hierarchy, he separated system from environment, decomposing them from top level to lower level, and the whole system will be decomposed to a tree hierarchy like a pyramid. The feature of AHP is that it mathematize and systematize thinking process so that people can accept it easily. As for this method, it neither simply pursues advanced mathematical knowledge nor emphasizes logical reasoning of qualitative behavior. Instead it combines quantitative method together with qualitative method to make the complex system clear. Decision problems with multi goals and multi rules are decomposed into comoared problems with single goal and multi-levels, and then simple mathematics can be added to it.

\section{2) The basic idea of $A H P$}

According to professor Saaty, each large system can be divided into small ones in terms of space and time. Start from the feature of hierarchy, he separated system from environment, decomposing them from top level to lower level, and the whole system will be decomposed to a tree hierarchy like a pyramid.

When it comes to resolving problems, AHP decomposes the whole system into various elements according to the nature of problem and the goal needing to be reached. Then arranging the elements into several levels from top to bottom according to the corelative effect and relationship among the elements. By comparing elements on each level according to certain rules, we can record the result into a matrix form. To figure out weight of importance of elements on the level and their importance to the overall goal by using some mathematic methods. Ranking them, and to analyze and resolve problems according to the sorting result.

\section{Construction of the evaluation model for the service competence of third-party logistics.}

TO change the evaluation system into evaluation model, analysis method combining quantitative and qualitative should be employed. While in this paper, we adopt AHP.

1) Determine the factors affecting evaluation of thirdparty logistics enterprises

The factors set of service competence $U=\{U 1$, $\mathrm{U} 2, \ldots \mathrm{Un}\}$ indicates that the top-level risk index includes $n$ main risk factors needing to be evaluated. The tertiary risk index included in the secondary risk index is Uij, indicating the $\mathrm{j}$ tertiary index in the secondary index as $\mathrm{i}$.

\section{2) Determine the evaluation set}

Evaluation set $\mathrm{V}=(\mathrm{V} 1, \mathrm{~V} 2, \ldots, \mathrm{Vm})$ indicates that division of levels are different according to different styles and affecting degree. Allowing for the fact that over detailed division is of no operational significance, so it's appropriate to take $\mathrm{m}=4 \sim 8$. In this paper, $\mathrm{m}=5$, evaluation set towards the service competence of third-party logistics enterprises is $\mathrm{V}=$ \{quite satisfied, satisfied, fair satisfied, basic satisfied, dissatisfied $\}$

\section{3) Determine the weight of various factors}

Comparing the importance of various elements on the same level after the hierarchical model is built and forming a comparing matrix between pairs. Then analyze the weight.Weight can be expressed in the form of $\mathrm{A}=(\mathrm{A} 1$, $\mathrm{A} 2, \ldots, \mathrm{An})$, within which Ai represents weight of secondary level in the $\mathrm{i}$. Assuming there are $\mathrm{L}$ factors on a certain level, $X=\{X 1, X 2, \ldots, X n\}$. We can take two factors $\mathrm{Xi}$ and $\mathrm{Xj}$ to represent effect or weight to the last level; and use Wij to represents the effect to last level. All the results can be wrote in the form of matrix $W=(w i j)_{m^{\prime} \times n^{\prime}}$, within which $m^{\prime}$ and $n^{\prime}$ represent amount of the secondary and tertiary evaluations. We call w judgment matrix. Value Wij according to Fig .1. 


\begin{tabular}{l} 
Measurement Wij \\
\hline 1 Having the same effect on the last level when comparing the two factors \\
3 Having greater effect on the last level when comparing the two factors \\
5 Having a somewhat greater effect on the last level when comparing the two factors \\
7 Having much greater effect on the last level when comparing the two factors \\
9 Having extreme greater effect on the last level when comparing the two factors \\
$2,4,6,8$ By comparison, if the effect is among the above two, then taking Wij as $2,4,6,8$ \\
\hline
\end{tabular}

Figure 1. meaning of the measurement Wij

Besides, judgment matrix should be checked out on its consistency. Methods as follows.

Index CI_-figure out the consistency of Wij

$$
C I=\frac{\lambda \max -s}{s-1}
$$

$\mathrm{CR}$ : Figure out the proportion of consistency of CR

$$
C R=C I / R I
$$

in the equation, $\mathrm{s}$ is the order to judge the form of matrix; $\lambda \max$ is the maximum eigenvalue to judge matrix w.

Refer to the average random one-time indicators RI. see Fig .2.

\section{$\begin{array}{llllllllllll}\mathrm{s} & 1 & 2 & 3 & 4 & 5 & 6 & 7 & 8 & 9 & 10 & 11\end{array}$

$\begin{array}{lllllllllllllllll}\text { RI } & 0 & 0 & 0.58 & 0.90 & 1.12 & 1.24 & 1.32 & 1.41 & 1.45 & 1.49 & 1.51\end{array}$

Figure 2. average random one-time indicators RI

When the judgment matrix is consistent entirely then $\mathrm{CR}=0$; when $\mathrm{CR}<0.1$, consistency of matrix $\mathrm{w}$ is thought to be acceptable; or we need to compare the pairs again to adjust the matrix to make it consistent.

4) Determine the matrix of evaluation and subordination

The relationship of all the evaluated units, elements, and grades, that is the blur relationship from $\mathrm{u}$ to $\mathrm{v}$, can be described in the matrix of evaluation and subordination.

(3)

$$
R=\left[\begin{array}{ccccc}
r_{11} & r_{12} & r_{13} & r_{14} & r_{15} \\
r_{21} & r_{22} & r_{23} & r_{24} & r_{25} \\
\cdots & \ldots & \ldots & \ldots & \ldots \\
r_{k 1} & r_{k 2} & r_{k 3} & r_{k 4} & r_{k 5}
\end{array}\right] K=(2,3,4,5,7)
$$

In the equation, $\mathrm{K}$ is the number of indicators of next level in each index system. rkm $(0 \leq \mathrm{rkm} \leq 1)$ represents the subordination of secondary and tertiary indicators to evaluation levels $\mathrm{m}(\mathrm{m}=1,2,3,4,5)$

5) Blur comprehensive evaluations

Blur comprehensive evaluation by composition operator

Combined process of weight $\mathrm{A}$ and subordinated matrix $\mathrm{R}$ can be described in the equation as below.

\section{$A$}

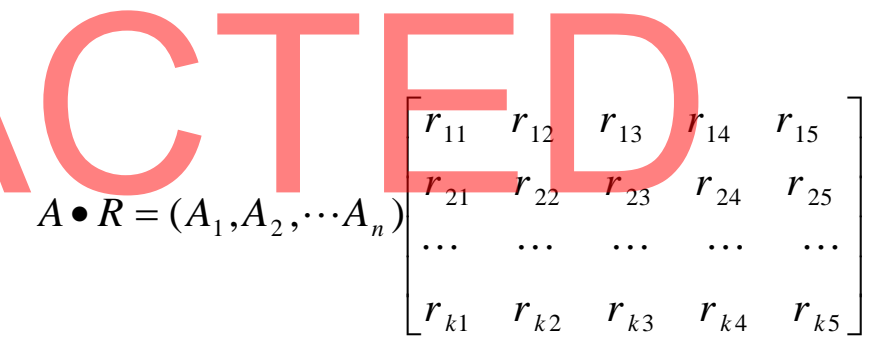

(4)

In the equation, indicators' membership to evaluation levels are expressed as b1,b2,b3,b4,b5; "." is the blur composition operator.

Blur comprehensive evaluation of secondary level

Membership of the primary indicator to the evaluating levels B can be gotten through the last evaluation. Take B as the matrix $\mathrm{Q}$ of secondary blur comprehensive evaluations. That is, $\mathrm{Q}=(\mathrm{B} 1, \mathrm{~B} 2, \ldots \mathrm{Bn}) \mathrm{T}, \mathrm{B}=\mathrm{A} \cdot \mathrm{Q}$. So results of the secondary blur comprehensive evaluation regarding the service competence of the third-party logistics providers.

Dealing with the evaluating results

First quantizing elements in the evaluating set $\mathrm{V}$ and then figuring out the results with equation $K_{i}=B_{i} V^{T}$. Service competence of third-party logistics of certain manufacturing enterprises can be obtained according to the results.

\section{CONCLUSION}

Faced with the fierce international and domestic competition, manufacturing enterprise should centralize its vigor and core resources on core business to consolidate and improve competitiveness so that to cultivate its own 
core competitiveness rather than concentrate on logistics since its not the core business, enterprise should outsource logistics to the third-party logistics service provider.

Production cost can be reduced with professional thirdparty logistics of large scale and systematic information. It can accelerate the speed of product coming to market and improve satisfaction of customers. Now under the background of globalization,manufacturing enterprises are facing more and more challenges besides opportunities. Actually it's better for enterprises to get rid of the complex logistics business if they can transfer it to the third-party logistics service provider so that it can have more energy and resources to strengthen its overall power and core competitiveness by concentrating on production process and customers' service. This measure will make manufacturing enterprises in our country in a leading position in the fierce international and domestic competition and seize greater development.
[1] Anonymous World-classlogistics: Change, 1995.

[2] Chen Jianchuan.Evaluations and Options of Logistics Service Providers[D].Wuhan:Huazhong University of Science and Technology Press, 2005.

[3] Wang Jinyun ,Gaoying.Research on the Options of Evaluation System by Third-party Logistics [J].Liaoning Financial Journal,2004, 6(35) : 32-35.

[4] Kuang Zhiwei.Research on the options of third-party logistics service provider[D].Wuhan:Wuhan University of Technology,2007.

[5] GDicksonan Analysis of Vendor Selection Systems and Decisions[J]. Journal of Purchasing, 1996,23(9):28-41.

[6] Lisa M.Ellram.The Supplier Selection Decision in Strategic partnership[J].Journal of Purchasing and MaterialS Management,1990, (26):8-14.

[7] Shiyu. Research on the Index System of Logistics Service in Automobile Manufacturing Enterprises [D] . Dalian : Dalian University of Technology, 2008.

[8] Li Qiwen,Lian Gongqian,Hu Jianbo,et al. Research on the Overall Management of Quality and 6tr Processing Management of Collaborative Business[J]Modern Manufacturing Engineering,2008(5

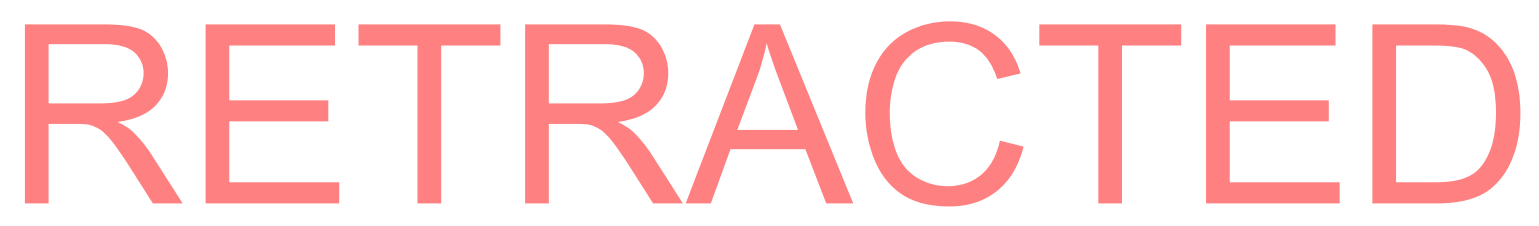

